\title{
Analysis of Indoor Natural Gas Leakage Explosion
}

\author{
Sun Liwen ${ }^{1}$, Li Guangpeng ${ }^{1,2^{*}}$ \\ ${ }^{1}$ School of Intelligent Manufacturing and Service, Shandong Institute of Commerce and Technology, Jinan, China \\ ${ }^{2}$ School of Mines, China University of Mining and Technology, Xuzhou, China
}

\begin{abstract}
The safety accident of indoor natural gas supply system is the process of natural gas leakage and diffusion, most of which are turbulent processes affected by many factors. When the natural gas leaks into the indoor confined space, it will mix with the air to form a mixture. When the oxygen in the natural gas and the air reaches a certain concentration range, combustion or explosion will occur when it meets the ignition source. This paper mainly introduces the influencing factors and calculation methods of the explosion limit of natural gas, and analyzes the calculation methods of the explosion limit of multi-component combustible mixed gas.
\end{abstract}

\section{Introduce}

With the continuous improvement of people's living standards, urban natural gas, like water, electricity and heat, is closely related to daily production and life[1]. As a kind of clean, environmental protection and high quality energy, natural gas will become the main source of natural gas for urban civil use in the future. The popularization and use of natural gas has greatly improved people's living standard and further accelerated the urbanization process[2]. However, with the continuous expansion of the city's gas supply range and the gradual growth of the number of users, indoor natural gas accidents have occurred frequently in recent years, causing many casualties and property losses. In order to protect the life and property safety of natural gas users, it is necessary to analyze the causes, rules and hazards of the accidents so as to find out the corresponding safety precautions. In this paper, the explosion limit of natural gas is studied, the factors affecting the explosion limit of multi-component mixed gas are analyzed, and the calculation method of explosion limit of natural gas is determined.

\section{Factors influencing the explosion limit of indoor natural gas}

In a gas mixture of natural gas and air, the amount of natural gas reduced to the point where it cannot form an explosive mixture is called the lower explosive limit of the gas. When the gas content increases to the point where it cannot form an explosive mixture, the content is called the explosive upper limit of the gas. The explosion limit of natural gas is affected by different factors, including temperature, pressure, purity, space size, ignition source and other factors.

\subsection{Natural gas temperature}

With the increase of the original temperature of the gasair mixture, the internal energy of the gas molecules will increase, and the number of active molecules will also increase, which will lead to the lower lower limit of the gas explosion and the higher upper limit of the gas explosion, thus resulting in the expansion of the explosion limit range of the gas-air mixture. This is because as the temperature of the system increases, the risk of natural gas explosion increases.

The influence of temperature on the explosion limit of natural gas is shown in Equations 1 and 2[3].

$$
\begin{aligned}
& L_{l_{(T)}}=L_{l_{(22)}} \text { 较 } 0.75(T-25) \text { 喽. } 18668 / H_{c} \\
& L_{h(T)}=L_{h(25)} \text { 閳 }+0.75(T-25) \text { 碊 } 4.1868 / H_{c}
\end{aligned}
$$

In the formula, $L_{h(T)}$ and $L_{h(T)}$ are the lower limit and upper limit of natural gas explosion corresponding to temperature $T$ respectively, $\% . \Delta H_{c}$ is the pure heat of natural gas combustion, $\mathrm{kJ} / \mathrm{mol} . T$ is combustion air mixture temperature, ${ }^{\circ} \mathrm{C}$.

\subsection{Natural gas pressure}

Generally speaking, with the increase of gas pressure, the explosion limit range of the gas will also increase.[4] According to the relevant experimental data, the pressure has a significant influence on the upper limit of explosion of natural gas, but a small influence on the lower limit of explosion of natural gas, which can be ignored in the calculation. This is because as the pressure increases, the molecular spacing of the gas will decrease. The molecules collide more often, making combustion reactions easier and increasing the explosive limits of natural gases.

\footnotetext{
* Corresponding author: 15098886718@163.com
} 
The influence of natural gas pressure on the upper limit of explosion can be shown in Formula 3[5].

$$
L_{h(p)}=L_{h(1 \mathrm{MPa})}+20.6(\lg p+1)
$$

In the formula, $p$ is absolute pressure, MPa .

Table 1. Influence of pressure on methane explosion limit

\begin{tabular}{|c|c|c|}
\hline $\begin{array}{c}\text { Initial pressure } \\
(\mathbf{P a})\end{array}$ & $\begin{array}{c}\text { Lower explosive } \\
\text { limit (\%) }\end{array}$ & $\begin{array}{c}\text { Upper } \\
\text { explosive limit } \\
\mathbf{( \% )}\end{array}$ \\
\hline $9.807 \times 10^{4}$ & 5.6 & 14.3 \\
\hline $9.807 \times 10^{5}$ & 5.9 & 17.2 \\
\hline $49.035 \times 10^{5}$ & 5.4 & 29.4 \\
\hline $12.259 \times 10^{6}$ & 5.7 & 45.7 \\
\hline
\end{tabular}

Table 1 shows that pressure has little influence on the lower limit of natural gas explosion and significant influence on the upper limit of natural gas explosion.

\subsection{Natural gas purity}

If natural gas is mixed with inert gas, it dilutes the concentration of the natural gas. When natural gas contains halogenated alkanes, it will dilute, isolate and cool the combustion explosion reaction. More importantly, it will increase the reaction ignition energy and inhibit the chemical reaction of natural gas combustion, which will also increase the explosion limit of natural gas, thus significantly reducing the explosion limit range of natural gas. At the same time, the increase of the concentration of inert gas in the air-burning mixture will reduce the oxygen concentration relatively. The oxygen concentration corresponding to the upper limit of natural gas explosion is already very small, which has a more drastic influence on the upper limit of natural gas explosion. Figure 1 shows the effect of the inert gas in the methane mixture on its explosive limit.

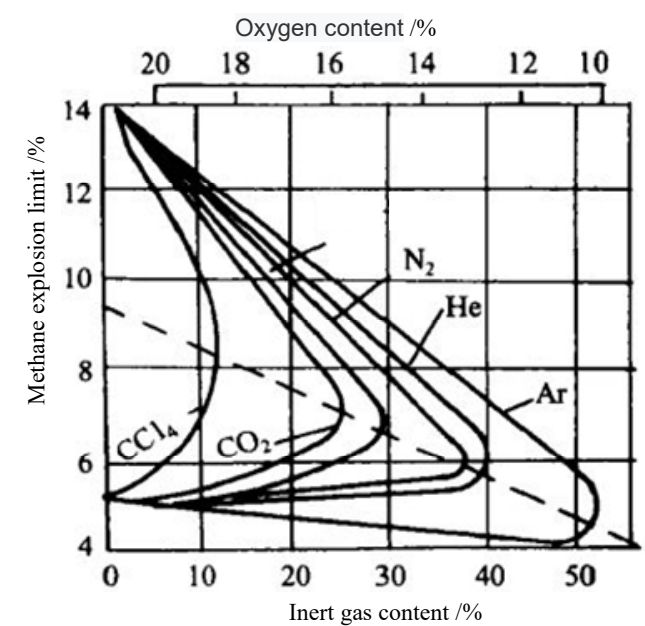

Figure 1. Effects of various inert gas concentrations on methane explosion limit

\section{4.space size}

Different container sizes can have different effects on the explosion limit of natural gas. With the increase of the thermal conductivity of the vessel surface area and the material on the vessel wall, the reaction heat dissipated outward will increase, and the energy needed to maintain the combustion reaction of natural gas will be greater, so the explosion limit range of the natural gas will be smaller. Correspondingly, if the surface area of the natural gas is smaller and the thermal conductivity of the wall material is smaller, the reaction heat dissipated outward will be smaller and the energy required will be smaller, and the explosion limit range of the natural gas will be larger.

\subsection{The ignition source}

The combustion explosion can occur only when the airburning mixture needs a certain amount of energy as the ignition source. Table 2. shows the explosion limit of methane and air formed by different ignition energies measured.

Table 2. Influence of ignition source intensity on explosive limit of methane and air mixture

\begin{tabular}{|c|c|c|}
\hline $\begin{array}{c}\text { Ignition source } \\
\text { intensity (J) }\end{array}$ & $\begin{array}{c}\text { Lower explosive } \\
\text { limit (\%) }\end{array}$ & $\begin{array}{c}\text { Upper explosive } \\
\text { limit (\%) }\end{array}$ \\
\hline 1 & 4.9 & 13.8 \\
\hline 10 & 4.6 & 14.2 \\
\hline 100 & 4.25 & 15.1 \\
\hline 1000 & 3.6 & 17.5 \\
\hline
\end{tabular}

If the energy of ignition source is increased, the lower limit of explosion of combustible mixture will be lower.The higher the explosion limit, the greater the range of the explosion limit and the greater the possibility of triggering a combustion explosion. The closer the ignition source is to the center of the mixed gas, the longer the action time is, and the larger the explosion limit range of natural gas will be.

\subsection{Other influencing factors}

In addition to the above main factors affecting the explosion limit of natural gas, the following factors will also affect the explosion limit of natural gas mixture, such as dry humidity of natural gas mixture, hot surface area of ignition source and contact time of natural gas mixture.

\section{Calculation of explosion limit of multi- component combustible mixture gas}

The premise of Richard Chartreuse's rule is that complex mixtures formed by the mixing of various pure natural gases within the explosion limit are assumed to remain within the explosion limit. Suppose that the volume percentages of $\mathrm{n}$ natural gases in the mixture are respectively $V_{1}, V_{2}, \ldots, V_{n}$, the oxygen supply values in the air required for the complete combustion of all kinds of pure natural gases are respectively $K_{1}, K_{2}, \ldots, K_{n}$. Since $1 \mathrm{~mol}$ pure natural gas requires $\mathrm{N} \mathrm{mol}$ oxygen for complete combustion, and the proportion of oxygen in the air is $\frac{21}{100}=\frac{1}{4.76}$, that is to say, $1 \mathrm{~mol}$ pure natural gas requires $4.76 \mathrm{~N} \mathrm{~mol}$ air for complete combustion.

Therefore, the explosion limit of the complex mixture formed by the mixing of $\mathrm{n}$ pure natural gases within the explosion limit is: 


$$
L=\frac{1}{4.76 a_{i=1}^{n} K_{i} V_{i}+1} ? 100 \%
$$

Equation 4 is used to calculate the lower explosion limit of the natural gas mixture, $K_{i}=2 N_{i}$. Calculate the upper limit of the explosion of the mixture, ${ }^{K_{i}}=\frac{N_{i}}{3}$.

$\mathrm{CH} 4, \mathrm{C} 2 \mathrm{H} 4, \mathrm{C} 3 \mathrm{H} 8$ and $\mathrm{C} 4 \mathrm{H} 10$ were taken as components of a natural gas mixture, and the original volume percentages of components were $95.17 \%, 2.2 \%$, $1.37 \%$ and $1.26 \%$, respectively. The explosion limit range of the mixed gas is $4.8 \%$ to $23 \%$ when the composition is made. The impact of methane content on the explosion limit of the natural gas is analyzed, as shown in Figure 2.

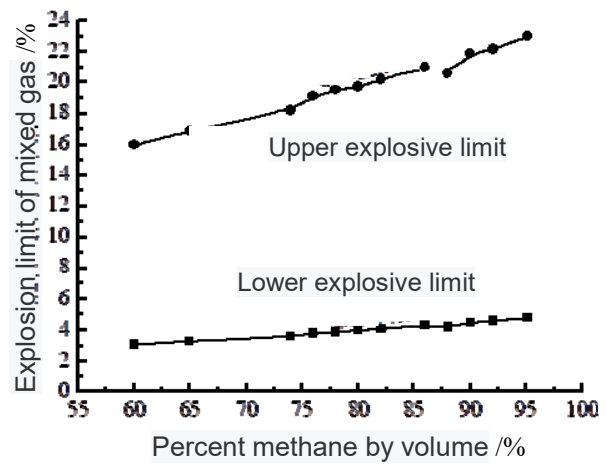

Figure 2. The effect of methane content on the explosive limit of the natural gas mixture

As can be seen from the figure, with the decrease of methane content in the natural gas mixture and the increase of other hydrocarbons content, the explosion upper limit and explosion lower limit of the natural gas mixture are reduced, and the explosion limit range is reduced. Moreover, the decrease of methane content in natural gas mixture has obvious influence on the explosion limit of natural gas mixture. When the methane content of a natural gas mixture is minimal or zero, the composition of the natural gas mixture may be considered as that of LPG.The influence of different contents of $\mathrm{C} 3 \mathrm{H} 8$ and $\mathrm{C} 4 \mathrm{H} 10$ on the explosion limit of natural gas mixtures is shown in Figure 3.

When the main components of the mixture are propane $(\mathrm{C} 3 \mathrm{H} 8)$ and butane $(\mathrm{C} 4 \mathrm{H} 10)$, the content of butane increases as the propane content decreases. The upper limit and lower limit of explosion of this mixture are reduced, and the influence on the upper limit of explosion of body mixture is more obvious, and the range of explosion limit of this mixture is also reduced.

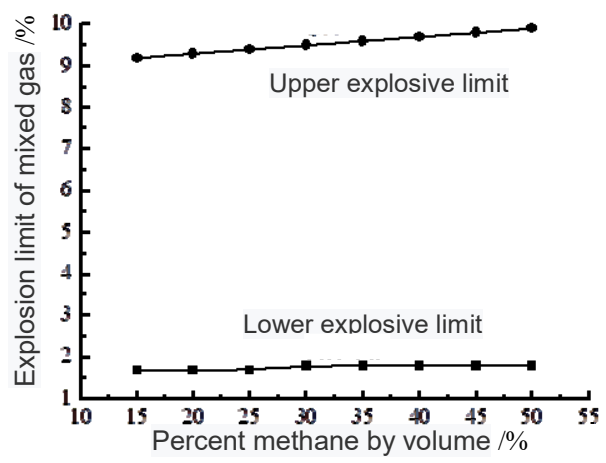

Figure 3. Effect of propane content on explosion limit of natural gas mixture
The gaseous group of a certain LPG is divided into: Hydrogen (H2) $5.0 \%$, ethane (C2H6) $7.0 \%$, ethylene $(\mathrm{C} 2 \mathrm{H} 4) 2.0 \%$, propane $(\mathrm{C} 3 \mathrm{H} 8) 50.0 \%$, propylene $(\mathrm{C} 3 \mathrm{H} 6)$ $7.0 \%$, butane (C4H10) 20.0\%, butane (C4H8) 4.0\%, and other $2.00 \%$. The lower and upper explosion limits of the LPG are calculated to be $2.03 \%$ and $10.45 \%$ respectively.

Since propane and butane are the main components of LPG, accounting for $70 \%$ or more of the volume percentage, the main components affecting the explosion limit of LPG are propane and butane. Among the components of LPG given, the volume percentage of other components is kept unchanged, and only the contents of propane and butane are changed to study their influence on the explosion limit of LPG. The results are shown in Table 3.

Table 3. Effect of volume content of propane and butane on explosion limit of LPG

\begin{tabular}{|c|c|c|c|c|c|c|c|}
\hline \multicolumn{2}{|c|}{$\begin{array}{c}\text { Volume } \\
\text { element (\%) }\end{array}$} & \multicolumn{4}{|c|}{$\begin{array}{c}\text { Explosion limit at standard } \\
\text { state (\%) }\end{array}$} & \multicolumn{2}{|c|}{$\begin{array}{c}\text { Explosion } \\
\text { limit of LPG } \\
(\%)\end{array}$} \\
\hline \multirow{2}{*}{$\mathrm{C}_{3} \mathrm{H}_{8}$} & \multirow{2}{*}{$\mathrm{C}_{4} \mathrm{H}_{10}$} & \multicolumn{2}{|c|}{$\mathrm{C}_{3} \mathrm{H}_{8}$} & \multicolumn{2}{|c|}{$\mathrm{C}_{4} \mathrm{H}_{10}$} & \multirow[t]{2}{*}{ lower } & \multirow[t]{2}{*}{ upper } \\
\hline & & lower & upper & lower & upper & & \\
\hline 58 & 12 & \multirow{8}{*}{2.1} & \multirow{8}{*}{9.5} & \multirow{8}{*}{1.5} & \multirow{8}{*}{8.5} & 2.09 & 10.56 \\
\hline 52 & 18 & & & & & 2.04 & 10.48 \\
\hline 46 & 24 & & & & & 2.00 & 10.40 \\
\hline 40 & 30 & & & & & 1.95 & 10.32 \\
\hline 30 & 40 & & & & & 1.88 & 10.19 \\
\hline 24 & 46 & & & & & 1.84 & 10.11 \\
\hline 18 & 52 & & & & & 1.81 & 10.03 \\
\hline 12 & 58 & & & & & 1.77 & 9.96 \\
\hline
\end{tabular}

The calculation results shown in Table 2.6 are consistent with those obtained in the previous section. When the effect of propane and butane on the explosion limit of natural gas is considered only, with the decrease of the percentage of the volume of propane $(\mathrm{C} 3 \mathrm{H} 8)$, the explosion limit and explosion limit of the natural gas are reduced, and the impact on the explosion limit of natural gas is more significant.

\section{Conclusion}

The factors influencing the explosion limit of natural gas (temperature, pressure, purity, vessel size, ignition source property) and their influencing characteristics are analyzed in this paper. According to the actual situation of indoor natural gas leakage, the calculation method of explosion limit of multi-component natural gas is analyzed, which provides a theoretical basis for the research and formulation of safety measures for indoor natural gas supply system.

\section{References}

1. Li Chunqing . The Analysis of the Causes of Indoor Gas Explosion Accident[J]. Urban Gas, 2019,(08),27-31

2. Qi Bao, Qin Fang, Yadong Zhang, Li Chen, Shigang Yang, ZhanLi. Effects of gas concentration and 
venting pressure on overpressure transients during vented explosion of methane- air mixtures[J] . Fuel .2016

3. Peng Shini, Xu Haidong. Calculation of Leakage Rate from Gas Pipeline[J] . Gas \& Heat, 2008(03):11-16

4. LU Jianying XI Lingling CAI Lei GUAN Yanwen YULu LI Wejje ZHANG Xiaohua WU Yong WANG Minye. Simulation Study on Leak Diffusion of Indoor Natural Gas[J] . Gas \& Heat, 2017,37(09):68-73

5. T. Chyzy, M. Mackiewicz. Simplified function of indoor gas explosion in residential buildings. 2017 , $87: 1-9$ 